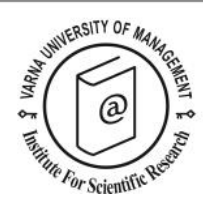

\title{
Do ambient scents in hotel guest rooms affect customers' emotions?
}

\author{
Oriol Anguera-Torrell ${ }^{1 *}$, Iván Álvarez León ${ }^{2}$, Alessandra Cappai ${ }^{2}$ \\ and Glòria Sanmartín Antolín ${ }^{2}$
}

\footnotetext{
${ }^{1}$ Barcelona School of Tourism, Hospitality and Gastronomy CETT - Universitat de Barcelona, Avinguda Can Marcet, 36-38, o8035 Barcelona (Spain). E-mail: oriol.anguera@cett.cat

${ }^{2}$ Barcelona School of Tourism, Hospitality and Gastronomy CETT - Universitat de Barcelona

* Corresponding author
}

\begin{abstract}
The introduction of ambient scents in different business facilities might be an effective strategy to influence customers' emotions and, ultimately, their experience. Yet, there is scant evidence on the effects of introducing ambient scents in hotels and, particularly, in hotels' private areas such as the guest rooms. Accordingly, this study aims to analyse the impact on customers' positive emotions when a pleasant ambient scent is introduced in a hotel guest room. To this end, a randomized control trial was conducted in a real four-star hotel in Barcelona in which two experimental groups $(\mathrm{N}=99)$ were invited to enter and experience a scented guest room and an identical but unscented room, respectively. The happiness level and the emotional valence of the experiment's participants were measured using a facial recognition technique. This methodological strategy represents one of the significant contributions of the study. The results show that, on average, individuals who entered the scented room were happier and had a better emotional state than individuals who entered the unscented room. These results suggest an important managerial implication for hoteliers who can improve the guests' experience by implementing a nonexpensive action and opens an avenue for future studies on scent marketing in hotels.
\end{abstract}

Keywords: Ambient scent; emotions; hotel guest room; facial recognition; happiness; emotional valence

Citation: Anguera-Torrell, O., Álvarez León, I., Cappai, A. \& Sanmartín Antolín, G. (2021). Do ambient scents in hotel guest rooms affect customers' emotions? European Journal of Tourism Research 27, 2701 


\section{Introduction}

Creating memorable guest experiences is key for firms in the hotel industry (Pizam, 2010) because the likelihood for hotel customers to recommend a hotel and to become loyal to it depends on the experience they had while in the establishment (Cetin \& Walls, 2016; Sukhu, Choi, Bujisic, \& Bilgihan, 2019). Experiences can be created at every point of contact between firms and their customers, and it is essential to consider the experience from a holistic perspective (Verhoef et al., 2009). The seminal work of Schmitt (1999) proposes that experiences can be generated by eliciting senses, feelings, emotions, and cognitive processes. In this sense, the correct management of customers' emotions is a necessary managerial practice to create an experience, add value for customers and increase their satisfaction (Ali, Hussain \& Omar, 2016; Hirschman \& Holbrook, 1982; Io, 2016; Torres, Wei, Hua, \& Chen, 2019).

Previous literature suggests that businesses can trigger customers' emotional responses by introducing ambient scents. Specifically, desirable behavioural and emotional reactions have been found in economic activities different from hotels when adding ambient scents in their premises (Bogicevic, Yang, Cobanoglu, Bilgihan, \& Bujisic, 2016; Ouyang, Behnke, Almanza, \& Ghiselli, 2017; Roschk, Maria, Loureiro, \& Breitsohl, 2017; Spangenberg et al., 1996). Nevertheless, the emotional reaction analysis of ambient scents has been a generally neglected topic in the academic literature on the hotel industry, being Chatterjee (2015) and Guillet, Kozak and Kucukusta (2019) two exceptions. In any case, no previous studies have specifically explored the emotional impact of the introduction of an ambient scent in a private area of a hotel, such as a guest room. Analysing how scenting a guest room can affect guests' emotions seems relevant for at least two reasons. First, emotional responses may differ in private spaces where individuals are alone or with their partner than in common areas where they can be seen or interact with others (Altman, 1975; Staats \& Hartig 2004; Staats, Van Gemerden \& Hartig 2010). Thus, it is not obvious that guests' emotions would positively react to an ambient scent in a guest room. Second, guest room features are vital to the generation of guests' experiences (Mitton, 2017), which highlights the importance of considering any room element, including intangible aspects like the smell, into the holistic guest experience (Ogle, 2009).

Accordingly, this study proposes to study how introducing a selected ambient scent in a hotel guest room can affect customers' emotions and, consequently, their experience. To this aim, the authors have designed a randomized control trial in a real four-star hotel in Barcelona to compare the experienced emotions of the participants who entered a scented hotel room with the emotions of the participants who entered to an identical but unscented room. In particular, the impact of a lavender scent on the happiness level and emotional valence of individuals have been studied.

Furthermore, this study also expands the literature on ambient scents by using a novel approach to measure emotions. Previous studies quantified emotions using subjective measures that came from individuals' self-reported answers on questionnaires. Conversely, this study inferred emotions using a facial recognition technology that allowed objectively measuring the emotions of individuals at each moment during the experiment.

\section{Theoretical framework}

\section{Ambient scents and emotions}

Hirschman and Holbrook (1982) stress that consumption does not only need to be analysed from an economic-rational perspective but also a hedonic one. Accordingly, they emphasize that the consumption experience is a phenomenon directly related to emotional responses. In the same vein, Schmitt (1999) highlights that managers should elicit positive emotions among their clients to manage consumption experiences. 
An emotional response is an affective mental short-term state that arises from a response to an antecedent stimulus event, either external or internal (Ekman, 1984; Frijda, 1986; Scherer, 2005). In this regard, stimulating the sense of smell seems to be a feasible way to trigger emotional responses. As different studies show, an odour can spark an emotional response since the olfactory system is connected to the same brain structure that also deals with the emotional memory (Aggleton \& Mishkin, 1986; Ellen \& Bone, 1998; Gulas \& Bloch, 1995; Herz, 2004; Herz, Eliassen, Beland, \& Souza, 2004; Pham, Faraji-Rad, Toubia, \& Lee, 2015). A possible channel to explain such a relationship is that odours stimulate memories of the past, which can elicit emotional responses (Ferdenzi et al., 2013). Moreover, Willander and Larsson (2007) and Herz et al. (2004) show that memories evoked by odours are more emotional than memories induced by their visual or auditory counterparts.

Various authors have analysed the effects of the presence of an ambient scent on consumers' emotions and behaviours in different types of businesses. The results show that an introduction of an ambient scent yields (1) higher pleasure (Roschk et al., 2017); (2) more satisfaction (Bogicevic et al., 2016; Mattila \& Wirtz, 2001; Morrison, Gan, Dubelaar, \& Oppewal, 2011; Roschk et al., 2017); (3) higher willingness to pay (Kechagia \& Drichoutis, 2017); (4) greater spending (Guéguen \& Petr, 2006; Hirsch, 1995; Leenders, Smidts, \& El Haji, 2019; Morrison et al., 2011; Spangenberg et al., 1996); (5) greater intention to revisit the business (Doucé \& Janssens, 2013); (6) better evaluations (Leenders et al., 2019; Spangenberg et al., 1996; Spangenberg, Grohmann, \& Sprott, 2005); (7) lower perceived time spent in the business (Guéguen \& Petr, 2006; McDonnell, 2002; Morrison et al., 2011; Spangenberg et al., 1996); (8) more social interactions in crowded rooms (Zemke \& Shoemaker, 2007); and (9) higher consumer exploratory behaviour (Orth \& Bourrain, 2005). Most of these studies employ an experimental setup, including control and treatment groups, and they analyse behavioural responses and, to a lesser extent, emotional reactions to ambient scents. In any case, emotions are the channel to explain behavioural responses according to Mehrabian and Russell's (1974) model from environmental psychology, which assumes that a stimulus, such as an ambient scent, can affect customers' emotional states that, in turn, influence customers' behavioural responses.

Furthermore, and beyond the strand of the literature examining the introduction of scents in businesses, there also exists evidence relating odours and emotions. For instance, Ferdenzi et al. (2011) highlight an association between odours and the emotions of happiness and well-being across different cultures. Other studies have also evaluated the effect of odour perception on happiness, which is considered to be one of the basic human emotions (Chrea et al., 2009; Desmet, 2006; Porcherot et al., 2010).

Regarding the hotel industry, there is limited evidence on the effects of ambient scents on hotel guests, which has not been obtained using an experimental setup. Chatterjee (2015) inquires guests of a hotel in India if they think that the ambient scent of this hotel's reception contributes to their experience, and the results suggest that this is the case. More recently, Guillet et al. (2019) ask the customers of a hotel in Hong Kong which type of emotions are evoked by the used ambient scent in the lobby and reception area of this hotel. In this study, participants self-reported that they believe that the ambient scent evokes happiness and delight in themselves, and sensuality. Consequently, these studies suggest that the introduction of ambient scents in the hotel's common areas might contribute to generating guests' experiences.

Moreover, the aforementioned previous literature analysing the impact of ambient scents in hotels only consider common areas of the buildings and ignore private spaces, such as the guest rooms. However, research in environmental psychology shows that privacy, understood as the absence of social 
interactions with strangers in the same space, can differently impact our affective processes (Staats \& Hartig, 2004; Staats, Van Gemerden, \& Hartig, 2010). Thus, it is important to analyse hotel guests' emotional reactions to ambient scents in their rooms because it is not straightforward to assume a positive emotional reaction to scenting a guest room. Besides, precedent studies suggest that scenting hotel guest rooms might be a persuasive practice since a good smell in the guest room might trigger an impression of cleanliness to customers (Ogle, 2009), and cleanliness is the most repeated criterion that guests use to evaluate a hotel (Atkinson, 1988; Knutson, 1988; Lewis, 1987; Lockyer, 2002). Similarly, Au, Buhalis, and Law (2014) find that the smell of guest rooms is critical to producing a high level of guest satisfaction. In this regard, adding a lavender scent in hotel guest rooms might be pertinent, since lavender is considered to be one of the most pleasant fragrances for humans (Moncrieff, 1966). In fact, previous studies have used the lavender scent in different experimental settings (Guéguen \& Petr, 2006; Mattila \& Wirtz, 2001; Morrin \& Ratneshwar, 2000).

\section{Types of emotions and their measurement}

There exists a great variation in the specific emotions that are analysed in the literature. For instance, Barsky and Nash (2002) propose a scale to study hotel guests' emotions that contains 16 different emotions, including comfort, security, and relaxation, among others. Similarly, Pullman and Gross (2004) consider various emotions in a hospitality setting that they classify into two categories: basic and VIP emotions. The former consists of positive emotional reactions, such as comfort, relaxed, happy, satisfied or amused, whereas the latter includes emotions such as sophisticated, privileged, important, or inspired. In the context of this article, the happy emotion seems to be relevant to be analysed after introducing an ambient scent because, as argued above, feelings of happiness can be induced by odours, and it is a positive emotional reaction. In addition, this paper also considers the emotional valence, which is a variable inferring whether the emotional state of an individual is positive or negative (Citron, Gray, Critchley, Weekes \& Ferstl, 2014) and can, therefore, be useful to infer its average emotional state. Concerning the measurement of emotions, they are usually quantified using subjective measures coming from either interviews or questionnaires (for instance, Mattila \& Enz, 2002). Moreover, customers' emotions data are usually gathered after and not while enjoying a consumption experience. Thus, the emotional responses might have diminished or been altered at the time of responding to questionnaires, since emotional responses are short-term states Thus, emotional reactions should be measured in real-time. Furthermore, the measures might not be completely objective since the individuals themselves are the ones who report their emotional level and might be influenced by features of the research instrument (Schwarz, 1999). Consequently, the measurement of emotional responses requires new approaches and methods that can process real-time and objective data.

In this sense, facial expression recognition allows for identifying immediate and spontaneous emotional responses to stimuli. Ekman, Friesen, and Tomkins (1971) pioneered facial coding to measure human emotions and proposed the Facial Affect Scoring Technique, which is a method that identifies six basic emotions: happiness, surprise, sadness, fear, anger, and disgust. In fact, emotions have been measured via facial expression analysis in seminal studies in the environmental psychology literature since the 9os (Ulrich, Dimberg, \& Driver, 1990), and it is a standard method in the psychology of emotions investigations (for instance, Scherer, Mortillaro \& Mehu, 2013). In the context of emotional reactions to scents, facial reactions occur quickly; precisely, between 400 and 1700 milliseconds after an odour presentation (Delplanque et al., 2009; He, Boesveldt, de Graaf, \& de Wijk, 2014). This emotional reaction can be detected directly by measuring muscle activity (Delplanque et al., 2009) or by assessing the emotions displayed on the face. To the best of the authors' knowledge, no research exists that studies hotel guests' emotions by applying the facial expression recognition method. 
Summary of the related literature and formulation of hypotheses

On the one hand, the literature shows that the introduction of ambient scents in different businesses is associated with several beneficial consumer outcomes such as positive emotions and desirable behaviours. Nevertheless, there is insufficient academic research on the effects of ambient scents on hotel premises, and more specifically, in hotel guest rooms. On the other hand, the literature has analysed and quantified a myriad of emotions through subjective measures obtained from questionnaires and interviews after a consumption experience takes place. The measurement of emotions using these techniques might be biased, as discussed above. The use of facial expression recognition technology seems to be a way to address this issue. By using this technique, this study measures the happiness level and the emotional valence of participants when exposed to a lavender scent in a hotel guest room, and proposes the following hypotheses:

Hypothesis 1: Individuals who experience a lavender-scented guest room display a higher level of happiness than individuals who experience an identical but unscented guest room.

Hypothesis 2: Individuals who experience a lavender-scented guest room display a higher level of emotional valence than individuals who experience an identical but unscented guest room.

\section{Methodology}

\section{Experimental setting}

A randomized control trial was conducted in two identical rooms of a four-star and business-oriented hotel in Barcelona (Alimara Hotel). This hotel is considered appropriate for this study because of its target clients. Business customers tend to attach a great deal of importance to comfort factors (Gundersen \& Heide, 1996), which can indeed include an ambient scent. The experiment used two identical standard rooms located on the fifth floor. Any standard room in this hotel has its bathroom and is like the one displayed in Figure 1. Each room has a window, but during the experiment, the curtains and shades were closed in both guest rooms to avoid emotional reactions in response to different weather and lighting conditions, and participants were asked not to open them.

The authors selected lavender as the ambient scent for the experiment because, as discussed in the theoretical framework, it is one of the most pleasant fragrances for humans. Two fragrance diffusers were located in each of the guest rooms: one on a bookshelf beside the bed and the other one on the bathroom vanity. The diffusers were placed in both rooms in order to not create any difference in terms of the presence of physical elements between both rooms. In any case, the scent diffusers were kind of hidden behind some hotel brochures. The diffusers were only working in one of the rooms (the treated room) and they were switched off in the other one (the control room). Therefore, the only difference between the two rooms was that in the treated one, there was an ambient scent of lavender, while in the control one, this ambient scent was not present. The diffusers were programmed to spread out the fragrance automatically every 10 minutes in the treated room. During the days the experiment was conducted, the diffusers in the treated room were switched on four hours before the first participant entered it. After each participant left the assigned room, the authors checked that the diffusers worked and that the room was neat and ready for the following participant.

\section{Participants}

This study recruited 140 participants from an undergraduate and a graduate degree in Tourism and Hospitality Management at a Spanish university and who were experienced travellers to participate in the experiment. Students from these majors were chosen for convenience but also to ensure that they had the knowledge and expertise to assess hotel room features. The authors made sure that none of the 
participants had allergies or asthma. Participants were told that the purpose of the experiment was to analyse how different room characteristics could influence guests' experience in hotel rooms.

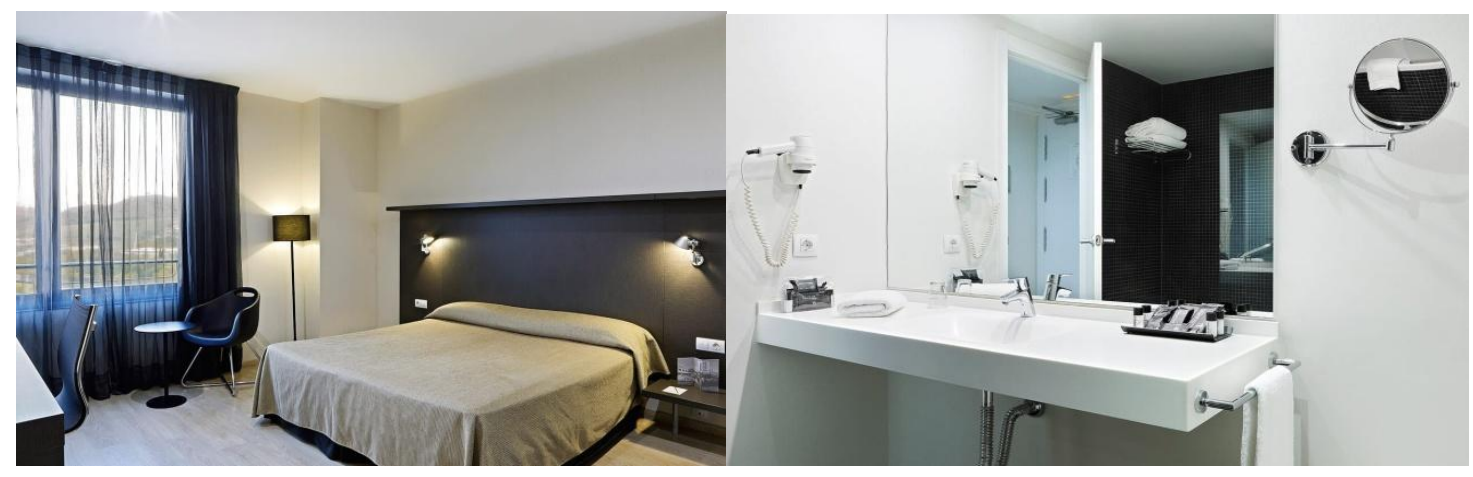

Figure 1. The guest room used in the experiment

The authors randomly assigned, with the help of a computer, 70 of the students to the lavender-scented room and 70 to the unscented room. That is, $50 \%$ of the participants were assigned to the treatment group, and 50\% were assigned to the control group. On the days in which the experiment was conducted, 99 individuals showed up. Therefore, the final sample comprised 99 individuals, of whom 55 belonged to the treatment group and 44 to the control one.

\section{Procedure}

On the days the experiment was conducted, the authors convened two different participants every 30 minutes. Upon arrival, the participants were received in the fifth-floor hall of the hotel and were told that during the experiment they were going to enter a guest room which they could experience as if they were a guest. They were also informed that they were going to wear a helmet that included a video camera to record their faces. Then, they were asked to sign a consent form, and a short video of them was registered to obtain a baseline of their facial expressions without any stimulus. In this regard, they were invited to answer three basic questions about themselves (name, age, and country of origin) while their face was recorded.

Next, the authors helped them to get into a helmet with a GoPro video camera installed $20 \mathrm{~cm}$ away from their faces. This camera pointed at their faces at eye level. When they felt comfortable with the helmet, each individual was taken to the assigned room (scented or unscented) and they were invited to enter and move freely as a guest within the room for one minute. Before entering, they were told that they were going to hear a doorbell indicating that they should leave the guest room after the time would expire.

Finally, when the individuals exited the room, they were asked to fill out a self-report questionnaire in which they provided some socio-demographic information that could potentially be associated with their emotional reactions. For instance, the individuals of certain countries of origin might react differently to a stimulus such as a lavender scent. This questionnaire also included an open question asking about which specific characteristics of the room, both physical or environmental, contributed to their experience while in the room. After they answered these questions, the authors thanked them for their participation. The experiment was conducted over three business days in May 2017. 


\section{Measurement of emotions and of socio-demographic information}

Emotions were measured using FaceReader technology, which is a software program able to infer the six basic emotions proposed by Ekman et al. (1971) from facial expressions: happiness, surprise, sadness, fear, anger, and disgust. FaceReader has been shown to be an effective technology to measure emotions (Terzis, Moridis, \& Economides, 2013). FaceReader combines two methods that work side by side: (1) face modelling and classification, and (2) deep face classification. Face modelling and classification is a method-based model that is used to synthesize the real face to an artificial face model. In its turn, deep face classification is a method that uses a deep artificial neural network to recognize patterns in the face (Bishop, 1995). This second method is not doing face modelling, and it directly classifies facial expressions from image pixels. The advantage of combining both methods is that FaceReader can analyse a face even if it is partly hidden. This study also used the continuous calibration option of the software program, which continuously adapts to test an individual's bias while analysing the face.

On the one hand, the authors focused on the happiness emotion, which is the only positive emotion that is provided by FaceReader. Sadness, anger, fear and disgust are considered to be negative emotions, and surprise can be either a positive or negative emotion. On the other hand, the authors also used the emotional valence, also determined by FaceReader, that indicates whether the emotional state of an individual is positive or negative. Specifically, the valence is calculated as the intensity of happiness minus the highest intensity among the negative emotions. The happiness and the emotional valence were estimated every 0.033 seconds.

A numerical variable named Happy $y_{i c}$ was created, which equals the mean level of happiness across the 60 seconds the experiment lasted for an individual $i$ and whose country of origin is $c$. The possible values for this variable range between o and 1 , where the higher the values are, the higher the intensity of the emotion is. That is, Happyic equals o if the happy expression was completely absent and 1 if the happy expression was fully present.

Analogously, the authors created a numerical variable named Valenceic, which equals the mean level of the emotional valence across the 60 seconds for an individual $i$ and whose country of origin is $c$. The possible values for this variable range between -1 and 1 , where the higher the values are, the more positive the emotional state of an individual is. That is, Valenceic equals -1 if the emotional state of an individual was completely negative and 1 if it was completely positive.

Regarding the socio-demographic information, the following variables were created: Female $i$ is a dummy variable equal to 1 if an individual $i$ is female and o otherwise; $A_{g e}$ is a variable equal to the selfreported age of an individual $i$; Education $i$ is a dummy variable equal to 1 if the highest level of education attained by an individual $i$ is an undergraduate degree and o if it is a high school diploma; and Foreign_origin $i$ is a dummy variable equal to 1 if the individual $i$ 's reported country of origin is not Spain and o otherwise.

\section{Comparison between control and treatment groups}

As in any experiment, the control and the treatment groups need to be comparable in terms of observables (Stock \& Watson, 2012). The only difference between them should be that the treated individuals are exposed to a stimulus, whereas the control ones are not. To check that this is the case, the authors propose to regress each of the socio-demographic variables on a dummy variable indicating the inclusion of an individual to the treatment group. That is, per each observable socio-demographic variable, the following equation is estimated using ordinary least squares: 
where $i$ stands for an individual $i$; Variable $i$ is a variable equal to the considered socio-demographic variable (i.e. female gender, age, education, or foreign origin); Treated $i$ is a dummy variable that takes value 1 if the individual $i$ was assigned to the treatment group and o otherwise; and $\epsilon_{i}$ is the error term. To check that the treatment and control groups are very similar in terms of observables, the coefficient $\mu$ should not be statistically significantly different from o for each observable variable.

Validity of introducing an ambient scent as the independent variable of the experiment

For the sake of the experiment's validity, it is essential that the participants did not guess the purpose of the investigation. Accordingly, the participants' answers to the open question asking about the specific factors affecting participants' experience during the experiment were individually analysed. In particular, any answer that referred to any aspect directly attributable to the ambient scent was independently coded. Ideally, none of these answers should be coded with such a category.

\section{Identification strategy}

To test the first hypothesis, the following equation is estimated by ordinary least squares:

$$
\text { Happy }_{i c}=\beta \text { Treated }_{i}+X^{\prime} \gamma+\rho_{c}+\epsilon_{i c}
$$

where Happyic is the mean intensity of happiness of individual i from the country of origin c across the 60 seconds that the experiment lasted; Treated $i$ is defined as in the previous subsection; $X$ is a vector of the individual socio-demographic variables; $\rho_{c}$ are country-of-origin fixed effects to control for originspecific characteristics that might affect the individual's level of happiness; and $\epsilon_{i c}$ is the error term. This equation is first estimated when neither covariates nor country-of-origin fixed effects are included, and only the treatment dummy and an intercept are introduced. This case would be equivalent to a two independent-samples t-test in which the mean of happiness for the treatment and the control group would be compared. This kind of analysis would be enough to analyse the first hypothesis of this study since the allocation of individuals to the treatment and control group was random. Nevertheless, the other control variables (female, age, education and country-of-origin fixed effects) are also later included as they can help reducing the variance of the error term, making the multiple regression model more efficient than a single regressor one (Stock \& Watson, 2012).

Therefore, the coefficient of interest is $\beta$ in each of the estimated specifications, and it can be interpreted as the causal impact that the ambient scent has on the average intensity of happiness. If it is positive and statistically significant, it means that the ambient scent increases the happiness level of the participants by the estimated $\beta$, on average, and that the first hypothesis can be confirmed.

Likewise, an analogous econometric model of equation (2) can be used to test the second hypothesis. That is, the following equation is proposed to be estimated by ordinary least squares:

$$
\text { Valence }_{i c}=\beta \text { Treated }_{i}+X^{\prime} \gamma+\rho_{c}+\epsilon_{i c}
$$

where Valence $_{i c}$ is the mean level of the emotional valence of an individual $i$ from the country of origin c across the 6o seconds that the experiment lasted; and the other variables are defined as in equation (2). As in the previous subsection, the coefficient of interest is $\beta$. If it is positive and statistically significant, this means that the ambient scent in the room increases the emotional valence of individuals by the estimated $\beta$, on average, and that the second hypothesis can be confirmed. 


\section{Results}

Profile of the participants

The majority of the participants $(81.8 \%)$ are female, and they are rather young, with an average age of 22.5 years. Regarding the highest level of education attained, $42.4 \%$ of the participants received an undergraduate degree in the past. Foreigners account for $34.3 \%$ of the participants. The specific countries of origin of the participants are the following: Brazil, China, Dominican Republic, Ecuador, Spain, India, Italy, Korea, Paraguay, Peru, Portugal, Venezuela, and the United States of America.

Table 1. Descriptive statistics

\begin{tabular}{lccccc}
\hline & Observations & Mean & SD & Min. & Max. \\
\hline Female & 99 & 0.818 & 0.388 & 0 & 1 \\
Age & 99 & 22.515 & 3.262 & 18 & 30 \\
Education & 99 & 0.424 & 0.497 & 0 & 1 \\
Foreigner & 99 & 0.343 & 0.477 & 0 & 1 \\
\hline
\end{tabular}

Adequate randomization between the control and the treatment groups

Table 2 shows the estimates of equation (1). The coefficient $\mu$ is not statistically significant for any of the regressed socio-demographic variables and, thus, it can be claimed that the treatment and control groups are comparable.

Table 2. Comparability of treatment and control groups

\begin{tabular}{lllll} 
& $\mathbf{( 1 )}$ & $\mathbf{( 2 )}$ & $(\mathbf{3})$ & $\mathbf{( 4 )}$ \\
& Female & Age & Education & Foreigner \\
\hline Treatment & 0.041 & 0.068 & -0.055 & 0.005 \\
& $(0.079)$ & $(0.671)$ & $(0.101)$ & $(0.097)$ \\
Intercept & $0.795^{* * *}$ & $22.477^{* * *}$ & $0.455^{* * *}$ & $0.341^{* * *}$ \\
& $(0.061)$ & $(0.523)$ & $(0.076)$ & $(0.072)$ \\
\hline Observations & 99 & 99 & 99 & 99 \\
$R^{2}$ & 0.003 & 0.000 & 0.003 & 0.000 \\
\hline
\end{tabular}

Note: Coefficients are statistically different from $\mathrm{o}$ at the following levels: ${ }^{*} \mathrm{p}<0.1,{ }^{* *} \mathrm{p}<0.05,{ }^{* * *} \mathrm{p}<0.01$. Robust standard errors in parentheses

\section{Validity of the experimental setting}

The answers to the open question asking which specific features of the room had contributed to the participants' experience in the room were individually analysed. A large majority of participants, both from the control and the treated groups, answered that several room characteristics like room colours, lighting, or bed comfort contributed to their experience. In contrast, only three participants, who were from the treated group, alluded to pleasant smell as a factor that contributed to their experience. Therefore, it can be claimed that the vast majority of participants did not find out what the purpose of the experiment was, validating the experimental setting.

\section{Average effect of the ambient scent on happiness}

Across all the individuals, the mean of Happyic is 0.224 , the standard deviation is 0.163 and the minimum and maximum values are 0.015 and 0.749 , respectively. Table 3 reports the estimates of equation (2) and 
allows analysing the causal impact of the ambient scent on happiness. The first column shows the estimates when neither covariates nor country-of-origin fixed effects are included, and only the treatment dummy and an intercept are introduced. The second column reports the estimates when country-of-origin fixed effects are taken into account. Finally, the third column also incorporates female gender, age, and education as covariates.

The coefficient $\beta$ is positive and statistically significant in all the three columns which confirms the first hypothesis. Specifically, if the attention is focused on the last column of Table 3 , it can be affirmed that the individuals who entered the scented room have 0.095 more units of happiness than the individuals who entered the unscented room, on average. Thus, introducing an ambient scent in a guest room raises the average level of happiness of individuals.

Table 3. Average effect of the fragrance on happiness

\begin{tabular}{llll} 
& $\begin{array}{l}(\mathbf{1}) \\
\text { Happy }\end{array}$ & $\begin{array}{l}\text { (2) } \\
\text { Happy }\end{array}$ & $\begin{array}{l}\text { (3) } \\
\text { Happy }\end{array}$ \\
\hline Treatment & $\begin{array}{l}0.08^{*} \\
(0.031)\end{array}$ & $\begin{array}{l}0.094^{* * *} \\
(0.034)\end{array}$ & $\begin{array}{l}0.095^{* *} \\
(0.036)\end{array}$ \\
Female & & & 0.013 \\
& & & $(0.046)$ \\
Age & & & -0.004 \\
& & & $(0.006)$ \\
Education & & & 0.039 \\
& & & $(0.059)$ \\
Intercept & $0.191^{* * *}$ & \\
& $(0.019)$ & & \\
\hline Country-of-Origin Fixed Effects & No & Yes & 99 \\
Observations & 99 & 99 & 0.198 \\
$R^{2}$ & 0.032 & 0.191 & Yes \\
\hline
\end{tabular}

Note: Coefficients are statistically different from $\mathrm{o}$ at the following levels: ${ }^{*} \mathrm{p}<0.1,{ }^{* *} \mathrm{p}<0.05,{ }^{* * *} \mathrm{p}<0.01$

Robust standard errors in parentheses

Average effect of the ambient scent on the emotional valence

Across all the individuals, the mean of Valenceic is 0.152 , the standard deviation is 0.191 and the minimum and maximum values are -0.193 and 0.719 , respectively. Table 4 reports the estimates of equation (3) and allows studying the causal impact of the ambient scent on the emotional valence. Analogously as in Table 3, the first column shows the estimates when neither covariates nor country-of-origin fixed effects are included. The second column reports the estimates when country-of-origin fixed effects are introduced and, finally, the third column also includes female gender, age, and education as covariates. The coefficient $\beta$ is positive and statistically significant in all the columns with the exception of the first one, which is the least efficient specification. Again, if the attention is focused on the last column of Table 4, it can be affirmed that the individuals who entered the scented room have 0.083 more units of the emotional valence than the individuals who entered the unscented room, on average. These results allow confirming the second hypothesis. That is, the ambient scent does not only increase happiness, but also the emotional valence. 
Table 4. Average effect of the fragrance on the emotional valence

\begin{tabular}{|c|c|c|c|}
\hline & (1) & (2) & (3) \\
\hline & Valence & Valence & Valence \\
\hline Treatment & $\begin{array}{l}0.045 \\
(0.037)\end{array}$ & $\begin{array}{l}0.082^{* *} \\
(0.040)\end{array}$ & $\begin{array}{l}0.083^{*} \\
(0.042)\end{array}$ \\
\hline Female & & & $\begin{array}{l}0.008 \\
(0.050)\end{array}$ \\
\hline Age & & & $\begin{array}{l}-0.005 \\
(0.008)\end{array}$ \\
\hline Education & & & $\begin{array}{l}0.043 \\
(0.070)\end{array}$ \\
\hline Intercept & $\begin{array}{l}0.127^{* * *} \\
(0.022)\end{array}$ & & \\
\hline Country-of-Origin Fixed Effects & No & Yes & Yes \\
\hline Observations & 99 & 99 & 99 \\
\hline$R^{2}$ & 0.014 & 0.180 & 0.185 \\
\hline
\end{tabular}

\section{Discussion, conclusion and limitations}

\section{Discussion}

The results of this study show that the introduction of a selected ambient scent in a hotel guest room can elicit positive emotions in customers. These results were obtained by conducting a randomized controlled trial in which some individuals entered a scented hotel guest room, whereas the rest entered an identical hotel room but without any ambient scent. The participants' faces were recorded while they were inside the room. In this way, it could be inferred their emotions in real-time by using a facial expression recognition technique (Terzis et al., 2013). Specifically, the authors measured the individuals' intensity of happiness and emotional valence. The individuals who experienced the scented guest room displayed a higher intensity of happiness and of the emotional valence than the individuals who experienced the unscented room.

An explanation for these results is the fact that the sense of smell is directly connected to the limbic system, which is also responsible for emotional responses (Ellen \& Bone, 1998; Herz, 2004; Herz et al., 2004; Pham et al., 2015). Indeed, these results are aligned with other studies that have found an effect of ambient scents on desirable customers' emotions and behaviours (e.g., Bogicevic et al., 2016; Leenders et al., 2019, Mattila \& Wirtz, 2001; Roschk et al., 2017). Yet, this paper provides new insight since previous studies have omitted the effect of ambient scents in private spaces, such as a hotel guest room.

Moreover, in aforementioned previous studies, emotional data were collected by directly asking individuals through questionnaires after being exposed to a stimulus. However, an emotion is an affective mental short-term state that arises from a response to external or internal stimulus events (Ekman, 1984; Frijda, 1986; Scherer, 2005). That is, emotions evolve and, consequently, it is likely that the emotions that respondents are feeling when answering a questionnaire might have changed with respect to the moment at which they were exposed to a stimulus. Accordingly, this paper also spans the literature on the impacts of ambient scents and other atmospheric cues in businesses by proposing the use of a well-established methodology in the psychology of emotions investigations. This method applied over experiments' participants can measure real-time and objective emotional reactions. 
Conclusion and industry implications

The objective of this research was to empirically test if introducing a pleasant ambient scent in a hotel guest room could generate positive emotional reactions to guests. To this aim, this paper has conducted a randomized control trial in a real four-star hotel in Barcelona and used a facial recognition technique to measure emotional responses to the ambient scent. The undertaken analysis has allowed establishing that adding a lavender fragrance in hotel guest rooms can elicit happiness and a positive emotional valence to hotel guests.

These results might be crucial in a context in which hoteliers usually tend to focus on the physical features of guest rooms, such as huge dimensions, beautiful views, and a comfortable bed, to elicit customers' emotions and experiences (Ogle, 2009). However, this study empirically shows that ambient scents can create positive emotions in guest rooms while being a low-cost and easy measure to apply. This is important because the creation of positive emotions helps to create experiences (Schmitt, 1999) and to develop loyalty (Pullman \& Gross, 2004). Thus, a scent marketing strategy in hotel guest rooms has the potential to enhance customer experience, loyalty, and future bookings.

This scent strategy should go hand in hand with the application of smart solutions aimed at promoting guests' comfort and well-being, representing a solution to tackle guests' requirements and needs and to co-create their experience. For instance, guests could be able to choose a specific scent for their room that would go along with other choices such as lighting or music, or even an unscented room. Thus, if hotels aim to provide a holistic experience in the whole hotel building, it is essential to integrate an ambient scent in guest rooms.

\section{Limitations and future work}

Indeed, this study comes with some limitations. For instance, only a specific ambiance of a guest room in combination with a lavender scent was used. This does not allow generalizing the results and urges to study different combinations of scents in different types of hotels. For instance, it might very well be the case that a seaweed scent in a hotel room may negatively impact the guests' emotions in urban hotel, but positively affect them in a hotel facing the sea. In fact, Bosmans (2006) points out the importance that the scent be congruent with a product or service. Another limitation of this study is that the participants remained for only 60 seconds in the guest rooms. Future studies should analyse the effects of ambient scents on customers over a longer period of time. Finally, another important limitation is that the authors used a convenience sample composed of students. The generalization of the results might be amplified by using real hotel guests and, hence, further studies should be undertaken to generalize the results.

\section{References}

Ali, F., Hussain, K., \& Omar, R. (2016). Diagnosing customers experience, emotions and satisfaction in Malaysian resort hotels. European Journal of Tourism Research, 12, 25-40.

Aggleton, J. P., \& Mishkin, M. (1986). The amygdala: Sensory gateway to the emotions. In R. Plutchik \& H. Kellerman (Eds.), Emotion: Theory, research, and experience (pp. 281-299). New York: Academic Press.

Altman, I. (1975). The Environment and Social Behaviour: Privacy, Personal Space, Territory, and Crowding. Monterey, California: Brooks Cole

Atkinson, A. (1988). Answering the eternal question: What does the customer want. Cornell Hotel and Restaurant Administration Quarterly, 29(2), 12-14. 
Au, N., Buhalis, D., \& Law, R. (2014). Online complaining behaviour in mainland China hotels: The perception of Chinese and non-Chinese customers. International Journal of Hospitality and Tourism Administration, 15(3), 248-274.

Barsky, J., \& Nash, L. (2002). Evoking emotion affective keys to hotel loyalty. Cornell Hotel and Restaurant Administration Quarterly, 43(1), 39-46.

Bishop, C. M. (1995). Neural networks for pattern recognition. New York: Wiley.

Bogicevic, V., Yang, W., Cobanoglu, C., Bilgihan, A., \& Bujisic, M. (2016). Traveler anxiety and enjoyment: The effect of airport environment on traveler's emotions. Journal of Air Transport Management, 57, 122-129.

Bone, P. F., \& Ellen, P. S. (1999). Scents in the marketplace: Explaining a fraction of olfaction. Journal of Retailing, 75(2), 243-262.

Bosmans, A. (2006). Scents and sensibility: When do (in)congruent ambient scents influence product evaluations? Journal of Marketing, $70(3), 32-43$.

Cetin, G., \& Walls, A. (2016). Understanding the customer experiences from the perspective of guests and hotel managers: Empirical findings from luxury hotels in Istanbul, Turkey. Journal of Hospitality Marketing E Management, 25(4), 395-424.

Chatterjee, S. (2015). Olfactory branding: A new trend for defining brands through smell - a case of ITC Sonar Hotel in Kolkata, India. International Journal of Trade and Global Markets, 8(3), 196-206.

Chrea, C., Grandjean, D., Delplanque, S., Cayeux, I., Le Calvé, B., Aymard, L., Velazco, M. I., Sander, D., \& Scherer, K. R. (2009). Mapping the semantic space for the subjective experience of emotional responses to odours. Chemical senses, 34(1), 49-62.

Delplanque, S., Grandjean, D., Chrea, C., Coppin, G., Aymard, L., Cayeux, I., Margot, C., Velazco, M. I., Sander, D., \& Scherer, K. R. (2009). Sequential unfolding of novelty and pleasantness appraisals of odours: evidence from facial electromyography and autonomic reactions. Emotion (Washington, D.C.), 9(3), 316-328.

Desmet, P. M. A. (2006). Typology of fragrance emotions. In D. S. Fellows (Ed.), Excellence 20o6; Esomar world research papers (pp. 309 -320). Amsterdam: Esomar.

Doucé, L., \& Janssens, W. (2013). The presence of a pleasant ambient scent in a fashion store: The moderating role of shopping motivation and affect intensity. Environment and Behaviour, 45(2), 215-238.

Ekman, P. (1984). Expression and the nature of emotion. In K. R. Scherer \& P. Ekman (Eds.), Approaches to emotion (pp. 319-344). Hillsdale, NJ: L. Erlbaum Associates.

Ekman, P., Friesen, W. V., \& Tomkins, S. S. (1971). Facial affect scoring technique: A first validity study. Semiotica, 3(1), 37-58.

Ellen, P. S., \& Bone, P. F. (1998). Does it matter if it smells? Olfactory stimuli as advertising executional cues. Journal of Advertising, 27(4), 29-39.

Ferdenzi, C., Delplanque, S., Barbosa, P., Court, K., Guinard, J.-X., Guo, T., Roberts, S. C., Schirmer, A., Porcherot, C., Cayeux, I., Sander, D., \& Grandjean, D. (2013). Affective semantic space of scents. Towards a universal scale to measure self-reported odour-related feelings. Food Quality and Preference, 30(2), 128-138.

Ferdenzi, C., Schirmer, A., Roberts, S. C., Delplanque, S., Porcherot, C., Cayeux, I., Velazco, M. I., Sander, D., Scherer, K. R., \& Grandjean, D. (2011). Affective dimensions of odour perception: a comparison between Swiss, British, and Singaporean populations. Emotion (Washington, D.C.), 11(5), 1168-1181.

Frijda, N. H. (1986). The emotions. Cambridge: Cambridge University Press.

Guéguen, N., \& Petr, C. (2006). Odours and consumer behaviour in a restaurant. Hospitality Management, 25(2), 335-339.

Guillet, B. D., Kozak, M., \& Kucukusta, D. (2019). It's in the air: Aroma marketing and affective response in the hotel world. International Journal of Hospitality and Tourism Administration,20(1), 1-14. 
Gulas, C. S., \& Bloch, P. H. (1995). Right under our noses: Ambient scent and consumer responses. Journal of Business and Psychology, 10(1), 87-98.

Gundersen, M. G., \& Heide, M. (1996). Hotel guest satisfaction among business travellers: What are the important factors? Cornell Hotel and Restaurant Administration Quarterly, 37(2), 72-81.

He, W., Boesveldt, S., de Graaf, C., \& de Wijk, R. A. (2014). Dynamics of autonomic nervous system responses and facial expressions to odours. Frontiers in psychology, 5, 110.

Herz, R. S. (2004). A naturalistic analysis of autobiographical memories triggered by olfactory visual and auditory stimuli. Chemical Senses, 29(3), 217-224.

Herz, R. S., Eliassen, J., Beland, S., \& Souza, T. (2004). Neuroimaging evidence for the emotional potency of odour-evoked memory. Neuropsychologia, 42(3), 371-378.

Hirsch, A. R. (1995). Effects of ambient odours on slot-machine usage in a Las Vegas casino. Psychology $\mathcal{E}$ Marketing, 12(7), 585-594.

Hirschman, E. C., \& Holbrook, M. B. (1982). Hedonic consumption: Emerging concepts, methods and propositions. Journal of Marketing, 46(3), 92-101.

Io, M. U. (1982). Exploring the impact of hedonic activities on casino-hotel visitors' positive emotions and satisfaction. Journal of Hospitality and Tourism Management, 26, 27-35.

Kechagia, V., \& Drichoutis, A. C. (2017). The effect of olfactory sensory cues on willingness to pay and choice under risk. Journal of Behavioural and Experimental Economics, 70, 33-46.

Knutson, B. J. (1988). Frequent travellers: Make them happy and bring them back. The Cornell Hotel and Restaurant Administration Quarterly, 29(1), 83-87.

Leenders, M. A., Smidts, A., \& El Haji, A. (2019). Ambient scent as a mood inducer in supermarkets: The role of scent intensity and time-pressure of shoppers. Journal of Retailing and Consumer Services, 48, 270-280.

Lewis, R. C. (1987). The measurement of gaps in the quality of hotel services. International Journal of Hospitality Management, 6(2), 83-88.

Lockyer, T. (2002). Business guests' accommodation selection: The view from both sides. International Journal of Contemporary Hospitality Management, 14(6), 294-300.

Madzharov, A., Ye, N., Morrin, M., \& Block, L. (2018). The impact of coffee-like scent on expectations and performance. Journal of Environmental Psychology, 57, 83-86.

Mattila, A. S., \& Enz, C. A. (2002). The role of emotions in service encounters. Journal of Service Research, $4(4), 268-277$.

Mattila, A. S., \& Wirtz, J. (2001). Congruency of scent and music as a driver of in-store evaluations and behaviour. Journal of Retailing, 77, 273-289.

Mc Donnell, J. (2002). Sensorial marketing for those who can wait no longer. In Proceedings of the first international conference of sensorial marketing. Nice: The Academy French Marketing and Columbia University.

Mehrabian, A., \& Russell, J. A. (1974). An approach to environmental psychology. Cambridge, MA, US: The MIT Press.

Mitton, R. K. (2017, November 15). Ten ways to innovate transform a hotel's in-room experience [Blog post]. Retrieved from https://www.avaya.com/blogs/archives/2017/11/transform-a-hotels-inroom-experience.html

Moncrieff, R. W. (1966). Odours. London: Leonard Hill.

Morrin, M., \& Ratneshwar, S. (2000). The impact of ambient scent on evaluation, attention, and memory for familiar and unfamiliar brands. Journal of Business Research, 49(2), 157-165.

Morrison, M., Gan, S., Dubelaar, C., \& Oppewal, H. (2011). In-store music and aroma influences on shopper behaviour and satisfaction. Journal of Business Research, 64(6), 558-564.

Ogle, A. (2009). Making sense of the hotel guestroom. Journal of Retail and Leisure Property, 8(3), 159172. 
Orth, U. R., \& Bourrain, A. (2005). Ambient scent and consumer exploratory behaviour: A causal analysis. Journal of Wine Research, 16(2), 137-150.

Ouyang, Y., Behnke, C., Almanza, B., \& Ghiselli, R. (2017). The influence of food aromas on restaurant consumer emotions, perceptions, and purchases. Journal of Marketing E Management, 27(4), 405423.

Pham, M. T., Faraji-Rad, A., Toubia, O., \& Lee, L. (2015). Affect as an ordinal system of utility assessment. Organizational Behaviour and Human Decision Processes, 131, 81-94.

Pizam, A. (2010). Creating memorable experiences. International Journal of Hospitality Management, 29(3), 343.

Porcherot, C., Delplanque, S., Raviot-Derrien, S., Le Calve', B., Chrea, C., Gaudreau, N. \& Cayeux, I. (2010). How do you feel when you smell this? Optimization of a verbal measurement of odourelicited emotions. Food Quality and Preference, 21, 938 -947.

Pullman, M. E., \& Gross, M. A. (2004). Ability of experience design elements to elicit emotions and loyalty behaviours. Decision Sciences, 35(3), 551-578.

Roschk, H., Maria, S., Loureiro, C., \& Breitsohl, J. (2017). Calibrating 30 years of experimental research: A meta-analysis of the atmospheric effects of music, scent, and color. Journal of Retailing, 93(2), 228-240.

Scherer, K. R. (2005). What are emotions? And how can they be measured? Social Science Information, 44(4), 695-729.

Scherer, K. R., Mortillaro, M., \& Mehu, M. (2013). Understanding the Mechanisms Underlying the Production of Facial Expression of Emotion: A Componential Perspective. Emotion Review, 5(1), 47-53.

Schmitt, B. (1999). Experiential marketing. Journal of Marketing Management, 15(1-3), 53-67.

Schwarz, N. (1999). Self-reports: how the questions shape the answers. American psychologist, 54(2), 93.

Spangenberg, E. R., Crowley, A. E., Henderson, P. W., Spangenberg, E. R., Crowley, A. E., \& Henderson, P. W. (1996). Improving the store environment: Do olfactory cues affect evaluations and behaviours? Journal of Marketing, 6o(2), 67-80.

Spangenberg, E. R., Grohmann, B., \& Sprott, D. E. (2005). It's beginning to smell (and sound) a lot like Christmas: The interactive effects of ambient scent and music in a retail setting. Journal of Business Research, 58(11), 1583-1589.

Staats, H., \& Hartig, T. (2004). Alone or with a friend: A social context for psychological restoration and environmental preferences. Journal of Environmental Psychology, 24(2), 199-211.

Staats, H., Van Gemerden, E., \& Hartig, T. (2010). Preference for restorative situations: Interactive effects of attentional state, activity-in-environment, and social context. Leisure Sciences, 32,5, 401-417.

Stock, J. H., \& Watson, M. W. (2012). Introduction to econometrics. Boston, MA: Pearson.

Sukhu, A., Choi, H., Bujisic, M., \& Bilgihan, A. (2019). Satisfaction and positive emotions: A comparison of the influence of hotel guests' beliefs and attitudes on their satisfaction and emotions. International Journal of Hospitality Management, 77, 51-63.

Terzis, V., Moridis, C. N., \& Economides, A. A. (2013). Measuring instant emotions based on facial expressions during computer-based assessment. Personal and Ubiquitous Computing, 17(1), 43-52.

Torres, E. N., Wei, W., Hua, N., \& Chen, P. J. (2019). Customer emotions minute by minute: How guests experience different emotions within the same service environment. International Journal of Hospitality Management, 77, 128-138.

Ulrich, R. S., Dimberg, U., \& Driver, B. L. (1990). Psychophysiological Indicators of Leisure Consequences. Journal of Leisure Research, 22(2), 154-166.

Verhoef, P. C., Lemon, K. N., Parasuraman, A., Roggeveen, A., Tsiros, M., \& Schlesinger, L. A. (2009). Customer experience creation: Determinants, dynamics and management strategies. Journal of Retailing, 85(1), 31-41. 
Willander, J., \& Larsson, M. (2007). Olfaction and emotion: The case of autobiographical memory. Memory and Cognition, 35(7), 1659-1663.

Zemke, D. M. V., \& Shoemaker, S. (2007). Scent across a crowded room: Exploring the effect of ambient scent on social interactions. International Journal of Hospitality Management, 26, 927-940.

Received: $17 / 02 / 2020$

Accepted: 27/07/2020

Coordinating editor: Stanislav Ivanov 